\title{
PREDICTION OF METHANOL CONTENT IN NATURAL GAS WITH THE GC-PR-CPA MODEL
}

\author{
Martha Hajiw $^{\mathrm{a}, *}$, Antonin Chapoy ${ }^{\mathrm{b}}$, Christophe Coquelet ${ }^{\mathrm{a}}$, Gerhard Lauermann ${ }^{\mathrm{c}}$ \\ ${ }^{a}$ Mines ParisTech ,PSL University, CTP - Centre Thermodynamic of Processes , 35 rue Saint Honoré, 77305 \\ Fontainebleau Cedex, France \\ ${ }^{\mathrm{b}}$ Centre for Gas Hydrate Research, Institute of Petroleum Engineering, Heriot-Watt University, Edinburgh EH14 \\ $4 \mathrm{AS}, \mathrm{UK}$ \\ ${ }^{\mathrm{c}}$ Linde AG, Engineering Division, Dr.-Carl-von-Linde-Strasse 6-14, 82049 Pullach, Germany
}

Produced reservoir fluids are principally composed of hydrocarbons but contain also impurities such as carbon dioxide, hydrogen sulphide and nitrogen. These fluids are saturated with the formation water at reservoir conditions. During production, transportation and processing ice and/or gas hydrates formation may occur. Gas hydrate and ice formation are a serious flow assurance and inherently security issues in natural gas production, processing and transport. Therefore, inhibitors are usually injected as a hydrate inhibitor and antifreeze. For example, methanol is often used for hydrate inhibition or in some cases during start up, shut down or pipeline plug removal. Therefore impurities, water and methanol usually end up in natural gas conditioning and fractionation units. These units produce end user pipeline gas subject to local specifications and natural gas liquids like ethane, LPG or heaviers. This is why the accurate knowledge of methanol content at different operating conditions is important. In this study, a group contribution model, the GC-PR-CPA EoS [1] (Group Contribution - Peng-Robinson - Cubic-Plus-Association), is successfully applied for hydrocarbons systems containing methanol. Predictions of phase envelopes of binary systems as well as partition coefficients of methanol in hydrocarbons mixtures are in good agreement with experimental data

Keywords: Natural gas fractionation; Methanol content; Partition coefficient; Group contribution method

\footnotetext{
* Corresponding author:

E-mail: martha.hajiw@mines-paristech.fr Telephone: +33(0) 164694972.
} 


\section{INTRODUCTION}

Natural gas is principally composed of hydrocarbons (methane, ethane, propane...), but contain also impurities such as carbon dioxide, hydrogen sulphide and nitrogen. It is also saturated with the formation water. The presence of small molecules and water at transportation conditions is suitable to hydrates formation. Gas hydrates are serious flow assurance issue and to prevent their formation, methanol is injected as hydrate inhibitor. The different impurities, water and methanol are removed in different separation units. Purified natural gas may then go to a fractionation train to recover the different hydrocarbon products. However, small quantities remain in the natural gas and specifications limit the methanol content in the purified gas to $50 \mathrm{ppm}$ [2]. To optimise the different steps of separation and meeting the requirements, accurate knowledge of methanol concentration and phase behaviour in the different operation units is important. It must be pointed out that the systems of interest show non-ideal behaviour due to the combination of a non-polar and a polar component forming hydrogen bonds and an azeotrope. Modelling such behaviour is often a challenge. In the natural gas industry, correlations or the well-known Peng-Robinson cubic equation of state [3] are used. However in cubic EoS association interactions between molecules (hydrogen bonding) are not taken into account.

A group contribution model, called GC-PR-CPA, has been developed to predict phase behaviour of systems containing associating compounds (water and alcohols). It combines the Cubic-Plus-Association equation of state (CPA EoS) [4] and a modification of the group contribution model developed by Jaubert et al [5]. In the industry, methanol content is usually calculated with correlations. The aim of this combination is to have a predictive model for associating compounds. Compared to the original version of CPA-SRK model, the GC-PRCPA EoS is a predictive model: there is no need for additional experimental data or to readjust the model parameters to predict phase behaviour of binary and multicomponent systems. In parallel, there is no group for alcohols so far. In this work, the GC-PR-CPA model has been used to predict alkane - methanol phase diagrams but also methanol content for very low concentrations of methanol (from 10 to 1000 molar ppm) in two phase systems. It is therefore possible to calculate the partition coefficient at infinite dilution and consequently the relative volatility, which is required for methanol behaviour in distillation processes. In order to determine the possible extent of separation between the different compounds of a mixture, there must be a known difference in volatilities. With the relative volatility, it is possible to predict the relative ease of vaporization of the individual components. 


\section{THE GC-PR-CPA MODEL}

\subsection{Pure Compounds}

The CPA EoS combines a cubic equation of state (here the Peng-Robinson (PR) EoS [3]) and the association term from Wertheim's theory [6]. It is expressed here, in term of pressure for a pure compound (Eq. (1)):

$$
P=\frac{R T}{v-b_{i}}-\frac{a_{i}(T)}{v\left(v+b_{i}\right)+b_{i}\left(v-b_{i}\right)}-\frac{1}{2} \frac{R T}{v}\left(1+\rho \frac{\partial \ln (g)}{\partial \rho}\right) \sum_{i=1}^{N} x_{i} \sum_{A_{i}}\left(1-X_{A_{i}}\right)
$$

For non-associating compounds, the CPA EoS is reduced to the PR EoS. Parameters of the PR EoS and the association term are presented in Table 1.

Table 1: Parameters of PR-CPA EoS

\begin{tabular}{|c|c|c|c|}
\hline Parameters & Name & Unit & Reference \\
\hline $\mathbf{P}$ & Pressure & $\mathrm{Pa}$ & \\
\hline $\mathbf{T}$ & Temperature & $\mathrm{K}$ & \\
\hline $\mathbf{R}$ & Ideal gas constant & $\mathrm{J} \cdot \mathrm{mol}^{-1} \cdot \mathrm{K}^{-1}$ & \\
\hline $\mathbf{v}$ & Molar volume & $\mathrm{m}^{3} \cdot \mathrm{mol}^{-1}$ & \\
\hline $\mathbf{b}_{\mathbf{i}}$ & $\begin{array}{c}\text { Co-volume of the } \\
\text { component } \mathrm{i}\end{array}$ & $\mathrm{m}^{3} \cdot \mathrm{mol}^{-1}$ & [3] \\
\hline $\mathbf{a}_{\mathbf{i}}$ & $\begin{array}{l}\text { Attractive parameter } \\
\text { of the component } i\end{array}$ & $\mathrm{~J} \cdot \mathrm{m}^{3} \cdot \mathrm{mol}^{-2}$ & {$[3]$} \\
\hline$\rho$ & Density & {$[-]$} & \\
\hline $\mathbf{g}$ & $\begin{array}{c}\text { Radial distribution } \\
\text { function }\end{array}$ & {$[-]$} & [7] \\
\hline $\mathbf{x}_{\mathbf{i}}$ & $\begin{array}{c}\text { Mole fraction of the } \\
\text { component } i\end{array}$ & {$[-]$} & \\
\hline $\mathbf{X}^{\mathbf{A i}}$ & $\begin{array}{l}\text { Mole fraction of the } \\
\text { component i not } \\
\text { bonded to the site A }\end{array}$ & {$[-]$} & [4] \\
\hline
\end{tabular}


In this work, the three parameters of the PR EoS (the attractive parameter $a$, the co-volume $b$ and the Soave type alpha function parameter $C_{1}$ ), the association energy $\varepsilon^{A_{i} B_{i}}$ and the association volume $\beta^{\mathrm{A}_{\mathrm{i}} \mathrm{B}_{\mathrm{i}}}$ have been fitted to vapour pressure and saturated liquid density data for associating compounds, including methanol. PR-CPA parameters for methanol are given in Table 2.

Table 2 : PR-CPA parameters for methanol

\begin{tabular}{|c|c|c|c|c|c|c|c|c|}
\hline Compound & $\begin{array}{c}\mathbf{a}_{0} \\
\left(\mathbf{b a r} . \mathrm{L}^{2} \cdot \mathrm{mol}^{-2}\right)\end{array}$ & $\begin{array}{c}\text { b } \\
\left(\mathbf{L} \cdot \mathrm{mol}^{-1}\right)\end{array}$ & $\begin{array}{l}\mathrm{C}_{1} \\
(-)\end{array}$ & $\begin{array}{c}\varepsilon \\
(\text { bar.L.mol } \\
\end{array}$ & $\begin{array}{c}\beta \\
\left(10^{3}\right)\end{array}$ & $\begin{array}{c}\text { Temperature } \\
\text { range }(\mathbf{K})\end{array}$ & $\begin{array}{l}\Delta \mathrm{P} \\
(\%)\end{array}$ & $\begin{array}{l}\Delta \rho \\
(\%)\end{array}$ \\
\hline methanol & 4.929 & 0.032 & 0.770 & 201.75 & 40.20 & $176-506$ & 0.9 & 1.1 \\
\hline
\end{tabular}

According to the terminology of Huang and Radosz [8], the 2B association scheme has been applied for methanol.

\subsection{Mixtures}

When applying the equation of state for mixtures, mixing rules are introduced. In this work, the classical mixing rule (van der Waals one fluid theory) has been applied for $a(T)$ and $b$ (Eqs. (2) and (3)).

$$
\begin{gathered}
a(T)=\sum_{i=1}^{N} \sum_{j=1}^{N} x_{i} x_{j} \sqrt{a_{i}(T) a_{j}(T)}\left(1-k_{i j}\right) \\
b=\sum_{i=1}^{N} x_{i} b_{i}
\end{gathered}
$$

where $\mathrm{N}$ is the number of components in the mixture.

The binary interaction parameter $\mathrm{k}_{\mathrm{ij}}$ is defined in this work by a group contribution model. For systems with non-associating compounds (e.g. hydrocarbons mixtures), it is calculated with the PPR78 model. However it has been modified for binary systems with associating compounds (see our previous paper [1]), involving three group interaction parameters $\mathbb{C}_{k l}$, $\mathbb{D}_{k l}$ and $\mathbb{E}_{k l}\left(\mathbb{C}_{k l}=\mathbb{C}_{l k}, \mathbb{D}_{k l}=\mathbb{D}_{l k}\right.$ and $\left.\mathbb{E}_{k l}=\mathbb{E}_{l k}\right)$. It is defined by Eq. (4)

$$
k_{i j}(T)=\frac{-\frac{1}{2} \times S u m-\left(\frac{\sqrt{a_{i}(T)}}{b_{i}}-\frac{\sqrt{a_{j}(T)}}{b_{j}}\right)^{2}}{2 \frac{\sqrt{a_{i}(T) a_{j}(T)}}{b_{i} b_{j}}}
$$


with

- for non-associating compounds (Eq. (5), [5]):

$$
\text { Sum }=\sum_{k=1}^{N g} \sum_{l=1}^{N g}\left(\alpha_{i k}-\alpha_{j k}\right)\left(\alpha_{i l}-\alpha_{j l}\right) \mathbb{A}_{k l}\left(\frac{298.15}{T}\right)^{\left(\frac{\mathbb{B}_{k l}-1}{\mathbb{A}_{k l}}\right)}
$$

- for binary systems with associating compounds (Eq. (6), [1]):

$$
\text { Sum }=\sum_{k=1}^{N g} \sum_{l=1}^{N g}\left(\alpha_{i k}-\alpha_{j k}\right)\left(\alpha_{i l}-\alpha_{j l}\right)\left(\mathbb{C}_{k l} T^{2}+\mathbb{D}_{k l} T+\mathbb{E}_{k l}\right)
$$

It also necessary to define combining rules for systems involving associating compounds. The CR1 combining rule has been chosen for ((Eqs. (7) and (8), [9]).

$$
\begin{aligned}
& \varepsilon^{A_{i} B_{j}}=\frac{\varepsilon^{A_{i} B_{i}}+\varepsilon^{A_{j} B_{j}}}{2} \\
& \beta^{A_{i} B_{j}}=\sqrt{\beta^{A_{i} B_{i}} \beta^{A_{j} B_{j}}}
\end{aligned}
$$

The model is solved using the same procedure as for other equations of state (see appendix 1).

\section{RESULTS AND DISCUSSION}

Measurements of vapour-liquid equilibria of binary mixtures with methanol and of low methanol content in pure alkanes and hydrocarbons mixtures have been conducted for a Gas Processors Association (GPA) project [2]. Methanol content ranges from 10 to $1000 \mathrm{ppm}$. Two binary systems have been studied: the propane - methanol and n-butane - methanol systems in the range of temperatures from 313 to $443 \mathrm{~K}$. These systems exhibit an azeotrope at maximum pressure for certain condition of temperature. Predictions for phase diagrams and partition coefficient will be compared to experimental data. The results obtained by our model are also compared to those of another predictive type UNIFAC model. Different versions of the UNIFAC model have been tested. For instance, the PSRK-UNIFAC model has been used, but it predicts a heteroazeotrope instead of a VLE at the azeotropic composition. Due to the flatness of the bubble curve, a small change in pressure leads to the prediction of a LLE, that is phase instability, corresponding to the cusp on Figure 1. Among all possible UNIFAC 
models, the PR78 - MHV2 - UNIFAC model (Peng-Robinson EoS [3] with the modified Huron-Vidal mixing rule $[10,11]$ and a modified UNIFAC version for the MHV2 mixing rule [12]), is the best option even if it shows a small cusp too (Figure 1). It will be compared to the GC-PR-CPA EoS.

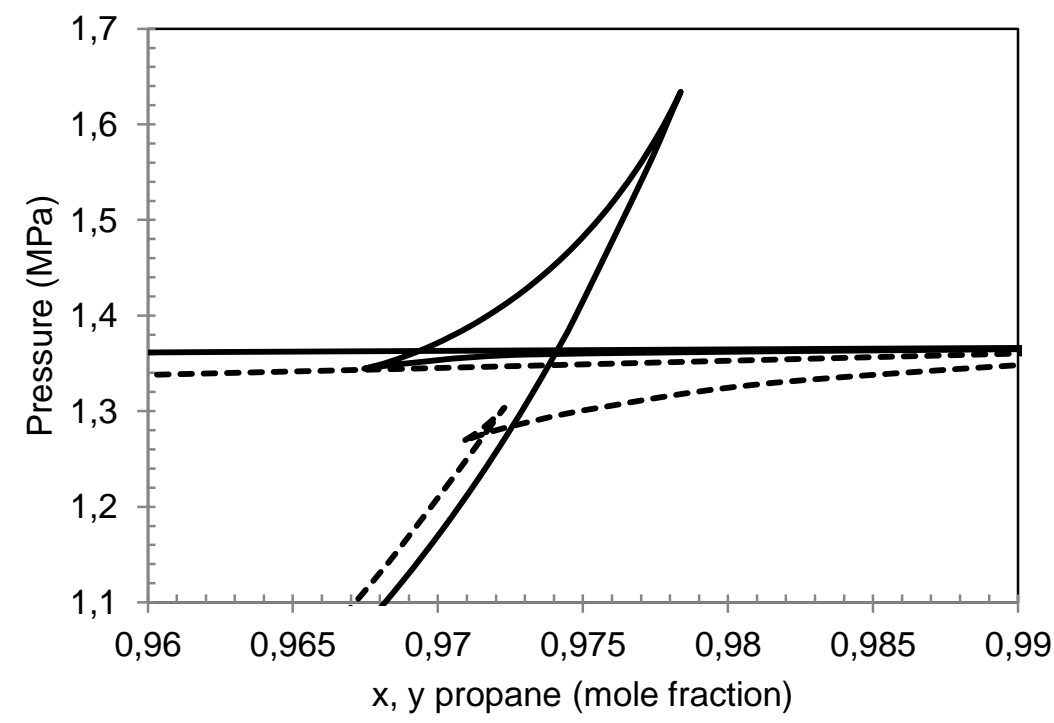

Figure 1 : Phase instability in prediction at azeotropic composition of the propane-methanol system. Solid lines: PSRK-UNIFAC model. Dashed lines: PR78-MHV2-UNIFAC model

To avoid phase instability, it is first important to well represent pure compounds.

\subsection{Binary systems}

Group parameters have been adjusted on VLE data of three binary systems: propane methanol [13], n-butane - methanol [14, 15] and n-hexane - methanol [16, 17]. They are given in Table 3.

Table 3 : Group parameters

\begin{tabular}{cccc}
\hline Groups (k) & $\mathbf{C}_{\mathrm{k}, \mathrm{CH} 3 \mathrm{OH}}\left(\mathbf{1 0}^{\mathbf{2}} \mathbf{P a}^{\left.-\mathbf{K}^{-2}\right)}\right.$ & $\mathbf{D}_{\mathrm{k}, \mathrm{CH} 3 \mathrm{OH}}\left(\mathbf{1 0}^{\mathbf{5}} \mathbf{P a}^{-\mathbf{- 1}}\right)$ & $\mathbf{E}_{\mathrm{k}, \mathrm{CH} 3 \mathrm{OH}}\left(\mathbf{1 0}^{\mathbf{7}} \mathbf{P a}\right)$ \\
\hline $\mathbf{C H}_{\mathbf{3}}$ & 3.14 & 2.41 & -0.776 \\
\hline $\mathbf{C H}_{\mathbf{2}}$ & -0.780 & 1.29 & 3.95
\end{tabular}

Predictions are evaluated for two binary systems studied in the GPA project or published in the literature: the propane - methanol system at 313.01 K (figure 2) and n-butane - methanol system at 323.2, (figure 3). It must be pointed out that at higher temperatures (from $400 \mathrm{~K}$ ) both models are not able to predict the equilibrium curve at compositions close to the 
azeotrope (Figure 4). Indeed, these models are not adapted close to critical and at supercritical temperatures ( $425.12 \mathrm{~K}$ for $\mathrm{n}$-butane). However, since the discontinuity is on both sides on the azeotrope, it means that the models predict two critical points as expected for a system with a maximum azeotrope.

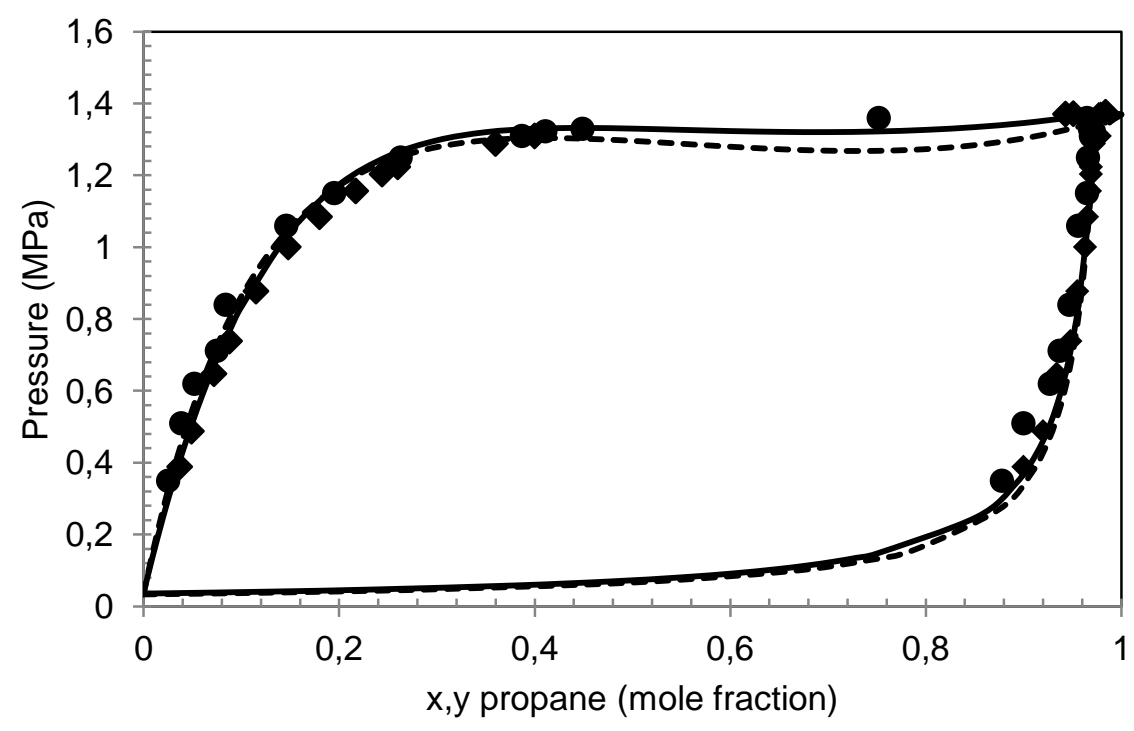

Figure 2 : Phase equilibria of the propane - methanol system at $313.01 \mathrm{~K} . \bullet[2]$ and $\bullet$ [13]. Solid lines: GC-PRCPA model. Dashed lines: PR78-MHV2-UNIFAC

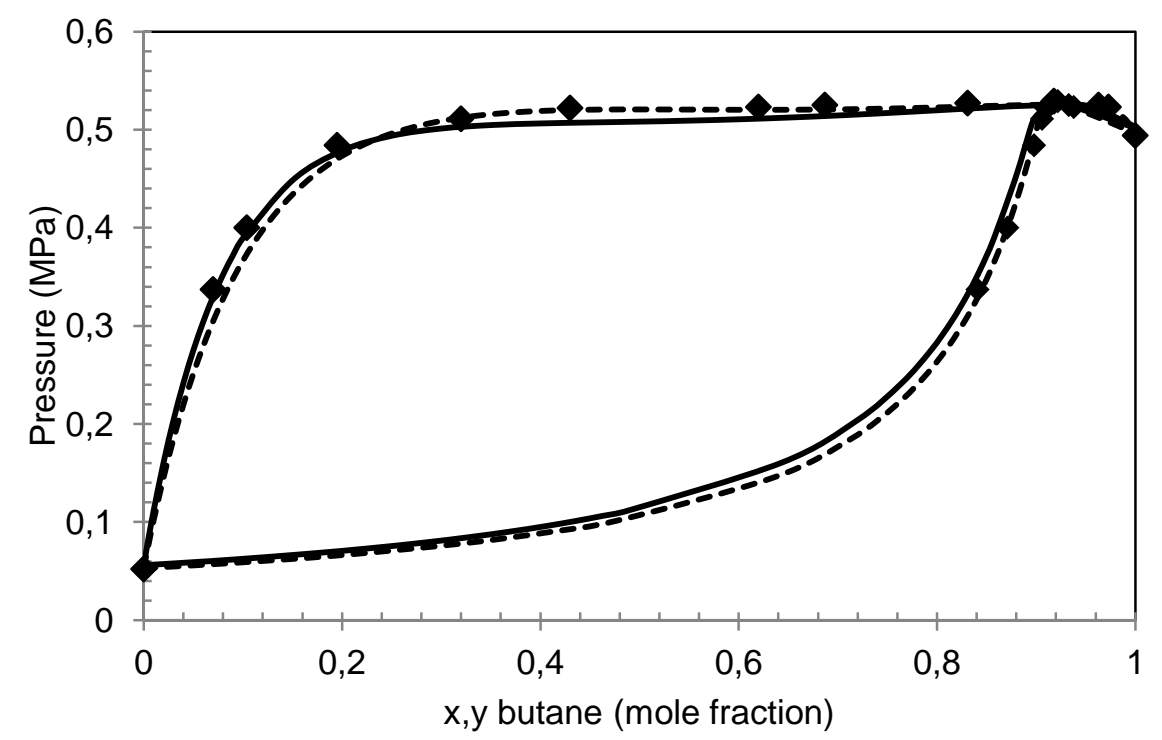

Figure 3 : Phase equilibria of the n-butane - methanol system at 323.2 K. [18]. Solid lines: GC-PR-CPA model. Dashed lines: PR78-MHV2-UNIFAC 


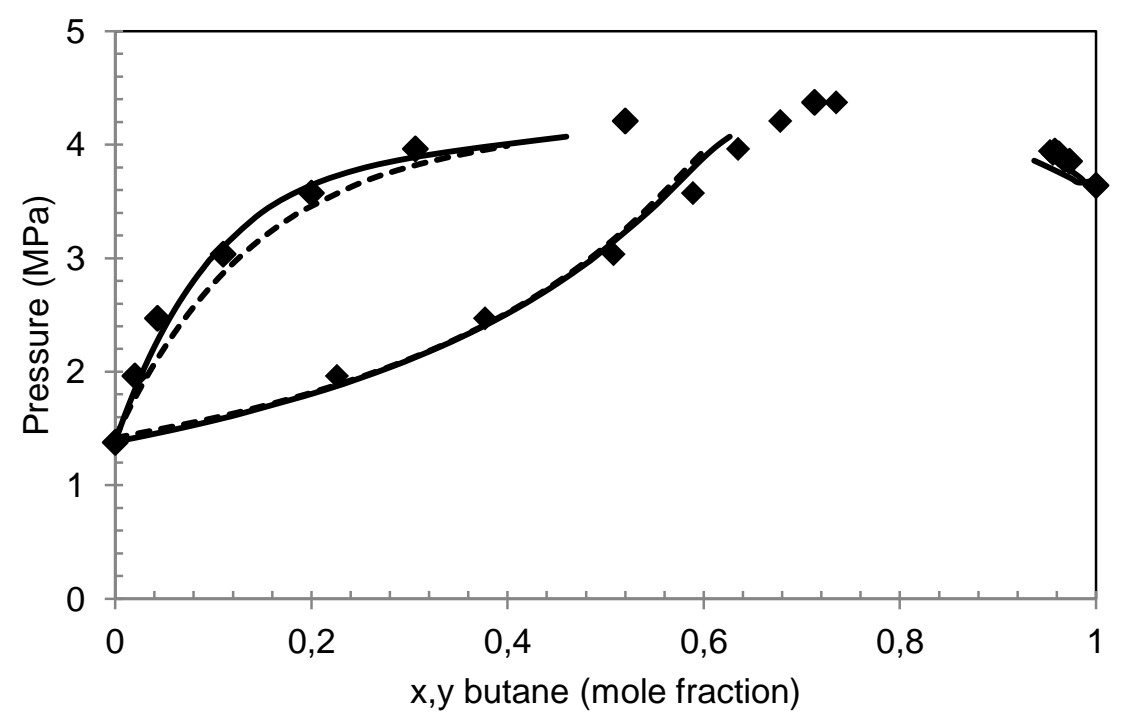

Figure 4 : Phase equilibria of the n-butane - methanol system at 423.09 K. [18]. Solid lines: GC-PR-CPA model. Dashed lines: PR78-MHV2-UNIFAC

$\mathrm{AAE}, \mathrm{AAD} \%$ and $\mathrm{BIAS} \%$ between experimental data and predictive models are presented in Tables 4 and 5 for all temperatures considered in this study for both systems.

Table 4 : Deviations on bubble pressure between experimental data and predictions

\begin{tabular}{|c|c|c|c|c|c|c|c|}
\hline & & & -MHV2-UN & & & SC-PR-CPA & \\
\hline & ems & $\begin{array}{c}\mathbf{A A E} \\
(\mathbf{M P a})\end{array}$ & AAD (\%) & BIAS (\%) & AAE (MPa) & $\operatorname{AAD}(\%)$ & BIAS (\%) \\
\hline $\mathrm{C}_{3}-$ & $\mathrm{H}_{3} \mathrm{OH}$ & 0.04 & 4.8 & -3.6 & 0.03 & 2.9 & -2.6 \\
\hline & $323.2 \mathrm{~K}$ & 0.01 & 2.0 & 1.6 & 0.01 & 2.0 & 0.5 \\
\hline & $373.2 \mathrm{~K}$ & 0.02 & 1.6 & 0.4 & 0.02 & 1.5 & 0.1 \\
\hline $\mathrm{C}_{4}-$ & $403.1 \mathrm{~K}$ & 0.05 & 2.3 & 1.2 & 0.04 & 1.7 & 0.1 \\
\hline $\mathrm{CH}_{3} \mathrm{O}$ & $423.1 \mathrm{~K}$ & 0.17 & 6.7 & 5.8 & 0.09 & 3.5 & 2.0 \\
\hline 11 & $433.2 \mathrm{~K}$ & 0.27 & 8.1 & 7.7 & 0.22 & 5.7 & 5.7 \\
\hline & $443.2 \mathrm{~K}$ & 0.17 & 4.3 & 3.5 & 0.24 & 4.9 & 1.6 \\
\hline
\end{tabular}

Table 5 : Deviations on methanol content between experimental data and predictions

\begin{tabular}{cccccccc}
\hline \multirow{2}{*}{ Systems } & \multicolumn{3}{c}{ PR-MHV2-UNIFAC } & \multicolumn{3}{c}{ GC-PR-CPA } \\
\cline { 2 - 8 } & $\begin{array}{c}\text { AAE (mole } \\
\text { fraction) }\end{array}$ & AAD $(\%)$ & BIAS $(\%)$ & $\begin{array}{c}\text { AAE (mole } \\
\text { fraction) }\end{array}$ & AAD (\%) & BIAS (\%) \\
\hline \multicolumn{2}{c}{$\mathbf{C}_{\mathbf{3}}-\mathbf{C H}_{\mathbf{3}} \mathbf{O H}$} & 0.01 & 16 & 12.4 & $3.8 .10^{-3}$ & 9.5 & 6.6 \\
\hline \multirow{2}{*}{$\mathbf{C}_{\mathbf{4}}-$} & $\mathbf{3 2 3 . 2} \mathbf{K}$ & 0.00 & 5.4 & -4.2 & 0.01 & 13 & 5.1 \\
$\mathbf{C H}_{\mathbf{3}} \mathbf{O H}$ & $\mathbf{3 7 3 . 2} \mathbf{K}$ & 0.02 & 9.1 & -8.4 & 0.02 & 11 & -4.2 \\
& $\mathbf{4 0 3 . 1} \mathbf{K}$ & 0.02 & 8.3 & -5.8 & 0.02 & 7.4 & 1.6
\end{tabular}




\begin{tabular}{lllllll}
$\mathbf{4 2 3 . 1} \mathbf{K}$ & 0.04 & 8.6 & -8.6 & 0.02 & 3.6 & -3.6 \\
$\mathbf{4 3 3 . 2} \mathbf{K}$ & 0.04 & 6.5 & -6.5 & 0.02 & 1.6 & 0.9 \\
$\mathbf{4 4 3 . 2} \mathbf{K}$ & 0.01 & 1.3 & 0.2 & 0.05 & 8.1 & 1.3 \\
\hline
\end{tabular}

Percentage errors in representing bubble pressure and methanol content are shown respectively on figures 5 and 6 for the n-butane - methanol system at $323.2 \mathrm{~K}$.

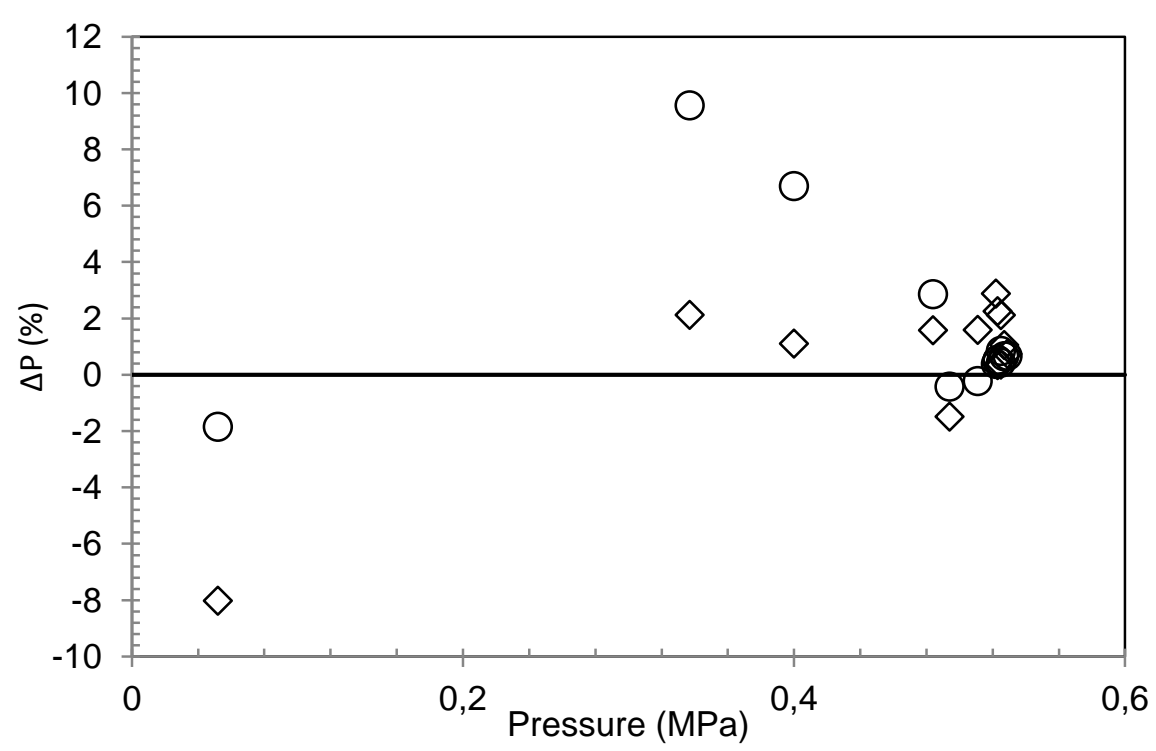

Figure 5 : Percentage error (BIAS) in the prediction of VLE pressure for the n-butane - methanol system at 323.2 K. [18]. $\diamond$ GC-PR-CPA EoS. $\bigcirc$ PR78-MHV2-UNIFAC model

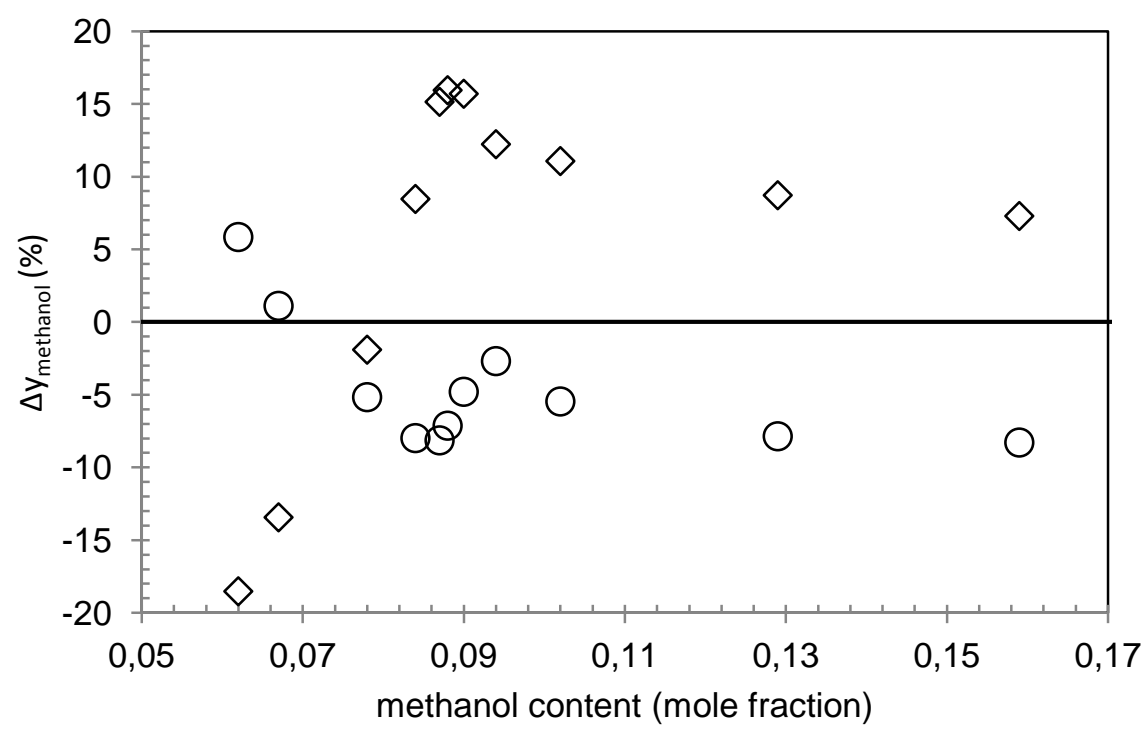

Figure 6 : Percentage error (BIAS) in the prediction of methanol content for the n-butane - methanol system at 323.2 K. [18]. $\diamond$ GC-PR-CPA EoS. $\bigcirc$ PR78-MHV2-UNIFAC model

Both models represent well phase equilibria of alkane - methanol systems. The PR78-MHV2UNIFAC model is better at lower temperatures while the GC-PR-CPA EoS is more accurate 
at higher temperatures. However, both models fail to represent the entire phase diagram at temperatures close to the critical region. It is one of the disadvantages of the CPA EoS.

\subsection{Partition coefficient}

For a vapour - liquid equilibrium, the ratio between the compositions of the component $\mathrm{i}$ in the vapour phase $\left(\mathrm{y}_{\mathrm{i}}\right)$ and in the liquid phase $\left(\mathrm{x}_{\mathrm{i}}\right)$ is called the partition coefficient (or $\mathrm{K}$ value). It is a function of the pressure, the temperature and composition. Composition dependence is of great importance in case of hydrogen bonding components being present in non-polar mixtures. The ratio of the partition coefficient between two compounds is called the relative volatility. This parameter is the most important one for the performance of a distillation column where the key components distribute between the products in the top and the bottom of the column and/or their behaviour show very strong concentration dependence towards infinite dilution. The evolution of the partition coefficient of methanol diluted in two mixtures of hydrocarbons has been studied in the GPA Research Report 219 [2] (Table 6) at different temperatures and pressures. The concentration of methanol in these mixtures is lower than $1000 \mathrm{ppm}$.

Table 6 : Composition of the two mixtures of hydrocarbons [2]

\begin{tabular}{ccc}
\hline Compounds & Mix 1 (mole fraction) & Mix 2 (mole fraction) \\
\hline Propane & 0.7359 & - \\
n-Butane & 0.1567 & 0.6189 \\
n-Pentane & 0.0874 & 0.3044 \\
n-Heptane & 0.0200 & 0.0767 \\
\hline
\end{tabular}

Values of partition coefficients estimated from experimental data and predicted are presented in Table 7 and two examples are shown on figures 7 and 8.

Table 7 : Values of partition coefficient

\begin{tabular}{|c|c|c|c|c|c|c|}
\hline Mixtures & Conditions & $\begin{array}{c}\text { Experimental } \\
\text { data }\end{array}$ & $\begin{array}{c}\text { PR78- } \\
\text { MHV2- } \\
\text { UNIFAC }\end{array}$ & $\Delta K_{M e O H}(\%)$ & $\begin{array}{c}\text { GC-PR- } \\
\text { CPA }\end{array}$ & $\Delta K_{\mathrm{MeOH}}(\%)$ \\
\hline \multirow{2}{*}{ Mix 1} & $\begin{array}{c}\mathrm{T}=353 \mathrm{~K} \\
\mathrm{P}=2.22 \mathrm{MPa}\end{array}$ & 1.89 & 1.32 & 30 & 1.83 & 3.2 \\
\hline & $\begin{array}{c}\mathrm{T}=366 \mathrm{~K} \\
\mathrm{P}=2.74 \mathrm{MPa}\end{array}$ & 1.74 & 1.36 & 22 & 1.72 & 1.1 \\
\hline 3Mix 2 & $\mathrm{~T}=394 \mathrm{~K}$ & 3.68 & 4.62 & -26 & 3.96 & -7.6 \\
\hline
\end{tabular}




$\mathrm{P}=1.4 \mathrm{MPa}$
$\mathrm{T}=416 \mathrm{~K}$
$\mathrm{P}=2.08 \mathrm{MPa}$

The GC-PR-CPA model is able to predict methanol low content behaviour in hydrocarbons mixtures as well as the partition coefficient at different temperatures and pressures and is much more reliable than the PR78-MHV2-UNIFAC model.

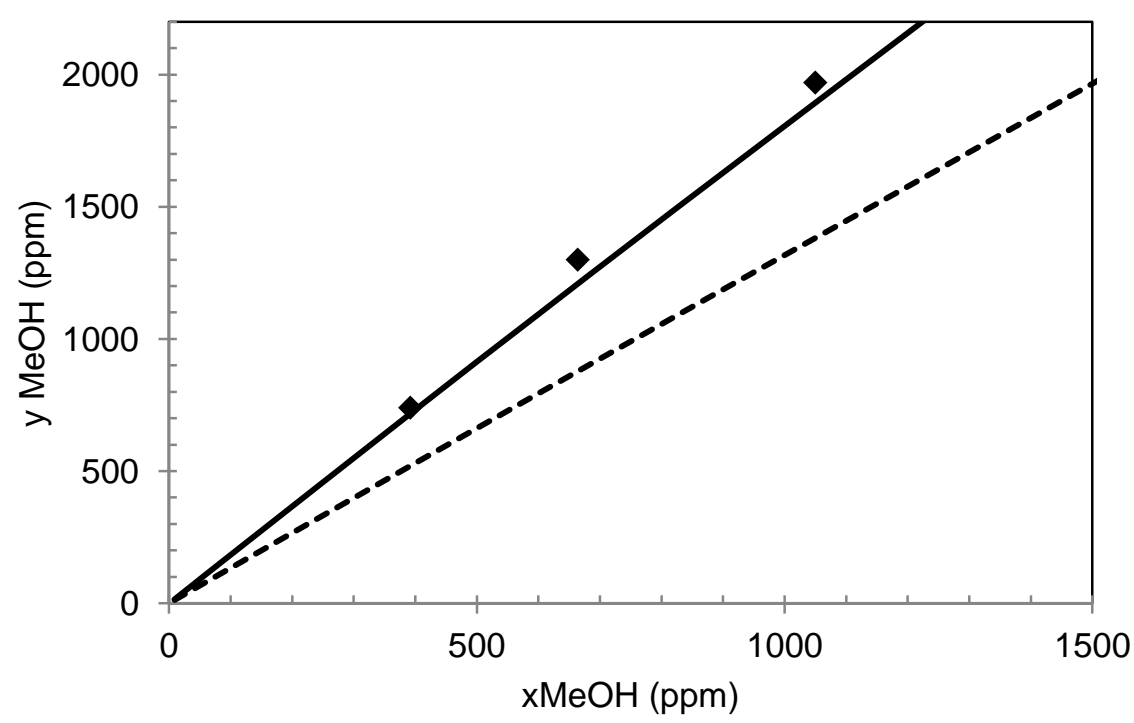

Figure 7 : Evolution of methanol composition in the vapour phase versus its composition in the liquid phase of

Mix 1 at $353 \mathrm{~K}$ and 2.22 MPa. Solid lines: GC-PR-CPA model. Dashed lines: PR78-MHV2-UNIFAC

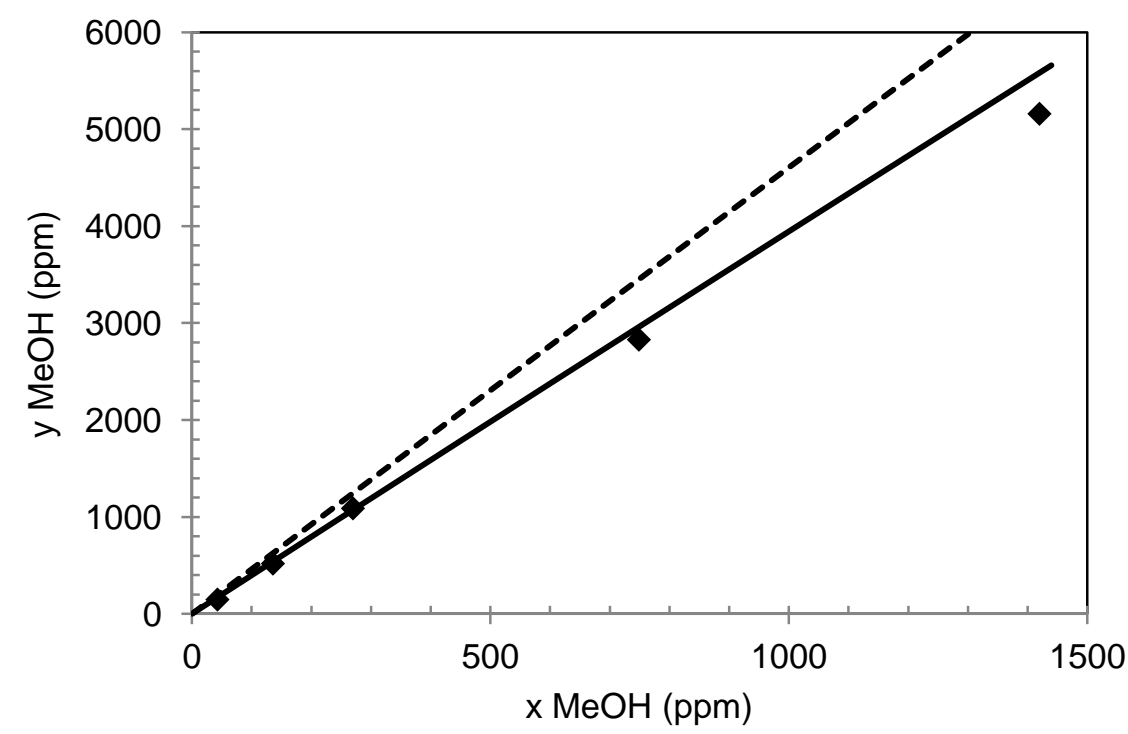

Figure 8 : Evolution of methanol composition in the vapour phase versus its composition in the liquid phase of Mix 2 at 394.2 K and 1.4 MPa. Solid lines: GC-PR-CPA model. Dashed lines: PR78-MHV2-UNIFAC

\section{CONCLUSION}


Experimental data measured during an important and relevant GPA project allow a better understanding of methanol distribution in a natural gas fractionation train. However, to estimate methanol content in a variety of hydrocarbons mixtures and at various operating conditions, accurate prediction models are of great importance. A reliable predictive model based on a group contribution method has been developed for systems with associating compounds. To evaluate its performance, predictions have been compared to experimental data and to another predictive model (PR78-MHV2-UNIFAC). The GC-PR-CPA EoS is able to predict phase envelopes of binary systems and to represent the azeotrope. However, it is not suitable close to critical conditions. Predictions of partition coefficients are also in good agreement with the experimental data.

\section{REFERENCES}

1. Hajiw, M., A. Chapoy, and C. Coquelet, Hydrocarbons - Water Phase Equilibria using the CPA Equation of State with a Group Contribution Method. The Canadian Journal of Chemical Engineering, 2014.

2. Courtial, X., et al., Methanol Distribution (as a contaminant) in Fractionation Products and Freeze Out Boundaries, G. RR-219, Editor. March 2013.

3. Peng, D. and D.B. Robinson, NEW 2-CONSTANT EQUATION OF STATE. Industrial \& Engineering Chemistry Fundamentals, 1976. 15(1): p. 59-64.

4. Kontogeorgis, G.M., et al., An equation of state for associating fluids. Industrial \& Engineering Chemistry Research, 1996. 35(11): p. 4310-4318.

5. Jaubert, J.N. and F. Mutelet, VLE predictions with the Peng-Robinson equation of state and temperature dependent $k(i j)$ calculated through a group contribution method. Fluid Phase Equilibria, 2004. 224(2): p. 285-304.

6. Wertheim, M.S., FLUIDS WITH HIGHLY DIRECTIONAL ATTRACTIVE FORCES .1. STATISTICAL THERMODYNAMICS. Journal of Statistical Physics, 1984. 35(1-2): p. 19-34.

7. Kontogeorgis, G.M., et al., Ten years with the CPA (Cubic-Plus-Association) equation of state. Part 1. Pure compounds and self-associating systems. Industrial \& Engineering Chemistry Research, 2006. 45(14): $p$. 4855-4868.

8. Huang, S.H. and M. Radosz, EQUATION OF STATE FOR SMALL, LARGE, POLYDISPERSE, AND ASSOCIATING MOLECULES. Industrial \& Engineering Chemistry Research, 1990. 29(11): p. 22842294.

9. Kontogeorgis, G.M., et al., Ten years with the CPA (Cubic-Plus-Association) equation of state. Part 2. Cross-associating and multicomponent systems. Industrial \& Engineering Chemistry Research, 2006. 45(14): p. 4869-4878.

10. Michelsen, M.L., A METHOD FOR INCORPORATING EXCESS GIBBS ENERGY MODELS IN EQUATIONS OF STATE. Fluid Phase Equilibria, 1990. 60(1-2): p. 47-58.

11. Michelsen, M.L., A MODIFIED HURON-VIDAL MIXING RULE FOR CUBIC EQUATIONS OF STATE. Fluid Phase Equilibria, 1990. 60(1-2): p. 213-219.

12. Larsen, B.L., P. Rasmussen, and A. Fredenslund, A MODIFIED UNIFAC GROUP-CONTRIBUTION MODEL FOR PREDICTION OF PHASE-EQUILIBRIA AND HEATS OF MIXING. Industrial \& Engineering Chemistry Research, 1987. 26(11): p. 2274-2286.

13. Galivel-Solastiouk, F., S. Laugier, and D. Richon, Vapor-Liquid Equilibrium data for the propanemethanol and propane-methanol-carbon dioxide system. Fluid Phase Equilibria, 1986. 28: p. 73-85.

14. Leu, A.D., et al., THE EQUILIBRIUM PHASE PROPERTIES OF THE PROPANE-METHANOL AND N-BUTANE-METHANOL BINARY-SYSTEMS. Canadian Journal of Chemical Engineering, 1992. 70(2): p. 330-334. 
15. Dell'Era, C., et al., Vapour-liquid equilibrium for the systems butane plus methanol, +2-propanol, +1butanol, +2-butanol, +2-methyl-2-propanol at 364.5 K. Fluid Phase Equilibria, 2007. 254(1-2): p. 49 59.

16. Goral, M., P. Oracz, and S. Warycha, Vapour-liquid equilibria - XIII. The ternary system cyclohexanemethanol-hexane at 303.15 K. Fluid Phase Equilibria, 1998. 152(1): p. 109-120.

17. Oracz, P. and S. Warycha, VAPOR-LIQUID-EQUILIBRIA .7. THE TERNARY-SYSTEM HEXANEMETHANOL-ACETONE AT 313.15 K. Fluid Phase Equilibria, 1995. 108(1-2): p. 199-211.

18. Courtial, X., et al., Vapor-liquid equilibrium in the n-butane plus methanol system, measurement and modeling from 323.2 to 443.2 K. Fluid Phase Equilibria, 2009. 277(2): p. 152-161.

APPENDIX 1: Flow chart for the VLE calculation for the GC-PR-CPA EoS

Read T, Pspec, pure component properties and GC-PR-CPA EoS constant parameters

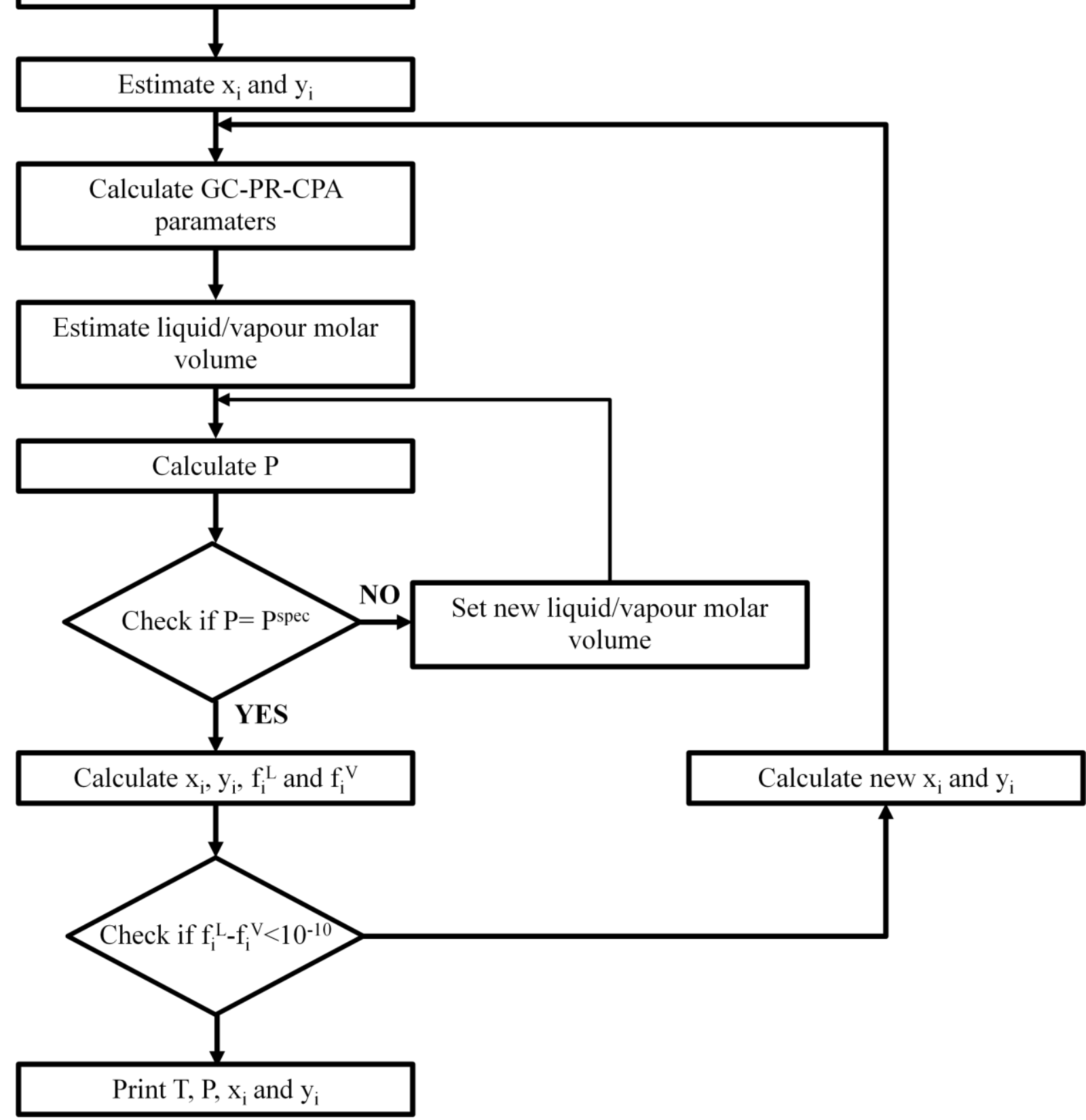

